\title{
Numerical Simulation for Soil-Superstructure Interactive System
}

\section{Ghulam A Hussainiªnd Nathan Vogelsang}

School of Natural and Built Environments, University of South Australia, Australia

\begin{abstract}
Geotechnical performances of soil superstructure systems are strongly dependent on the properties of the soil, and prediction of the performance of these systems in real conditions requires accurate modelling of soil parameter. It is vital to determine the risk of damage to structures, due to soil displacement by differing some of the soil parameters. The core objective of this project is to study the response of a soil-structure subjected to uniform loading. From this, the soil- structure stiffness can be easily obtained. For the basis of the analysis, the soil has been assumed first elastic with individual random variables such as Young's modulus and Poisson's ratio simultaneously. After the elastic displacement, known the plastic analysis conducted. For the analysis of this project, finite element models are developed in ABAQUS to simulate vertical uniform load of 3 kilo-Pascal ( $\mathrm{kPa}$ ) for elastic and $100 \mathrm{kPa}$ for plastic deformation. Results from the analysis discussed and comparison between the experimental values and theoretical values examined. The difference between elastic and plastic analysis checked against the displacement. The parametric study has indicated that the E- modulus of the soil and structure load have larger impact on the soil-structure response. Due to various variables of certain soil parameters, the selection of specific soil with few important variables were the centre of this study, to achieve more realistic results.(C)
\end{abstract}

Keywords: ABAQUS; Random variables; Finite element model; E-Modulus; Young's modulus; Poisson's ratio; Friction angle; Cohesion; Elastic and plastic analysis; Soil stiffness; Soil settlement

\section{Introduction}

Smith [1] mentions, the uncertainties affected by soil variability makes it more challenging and important to study the significant effect on soil structures. The stochastic approach to incorporate these uncertainties into the calculation of soil superstructure is one of the solutions which are investigated in this project. Only few variables studied during this research which are Young's modulus, Poisson's ratio, Friction angle and Cohesion. The purpose of this study is to incorporate the stochastic performance due to soil.

Hindmarsh clay may not be the core subject of previous research studies therefore, it is important to see the reactivity of local soilsuperstructure behavior and to assess the risks in the geotechnical design using Hindmarsh clay.

\section{Methodology}

\section{Limitations in this study}

The research is focused on the stiffness of a soil-structure system considering elastic and plastic behaviour of soil. The soil characteristic was assumed to be Hindmarsh clay, which mostly consists of silty clay composites. The size of the soil-structure considered was limited, as well as the type of load distribution on the sample which was uniformly distributed. The load combinations used in ABAQUS and the total analysis were conducted were limited to just over a 1000 trials. The research is limited to only four soil variables;

- Young's modulus and Poisson's ratio were used for elastic analysis

- Friction angle and Cohesion were added up to determine the plastic analysis. Due to limitations of soil variability only elastic and plastic analysis were conducted in ABAQUS.

\section{Testing of results}

Moghaddasi [2] used Monte-Carlo simulation to generate substantial number of models incorporating wide range of soil, foundation and structural parameters. They performed over 4 million time-history analyses over the adopted models. The results show that effect $s$ of foundation flexibility on the structure distortion and total displacement of the superstructure through comparisons between the responses of soil foundation structure models and corresponding fixed base models. Moghaddasi [2] studies, the response of the superstructure due to soil-foundation-structure interaction (SFSI) effects were examined using two response parameters:

-Structural distortion, $\mathrm{u}$, and Structural total displacement, u_str

\section{Theory}

\section{Settlement equations}

Smith [1], used few basic equations for the settlement equation used during this research is based on the elastic settlement for all types of soils due to a surface load which can be found from;

$$
S=\int_{0}^{z} \varepsilon_{z} d z
$$

Where $\varepsilon z=$ vertical strain

Smith [1] confirms that if the elastic body is of infinite depth, i.e. $\mathrm{z}=\mathcal{E}$, and the stress distribution is determined from the Boussinesq equation, the settlement equation can be simplified to:

$$
S=\frac{q B\left(1-v^{2}\right)}{E} I_{s}
$$

Where, $\mathrm{q}=$ Value of the udl $(\mathrm{kPa})$

$\mathrm{B}=$ Width of loaded area $(\mathrm{m})$ Poisson's ratio of the soil

$\mathrm{v}=$ Poisson's ratio of the soil

$\mathrm{E}=$ Elastic modulus of the soil $(\mathrm{MPa})$

Is=Settlement influence coefficient obtained from Table 1

$\mathrm{s}=$ Settlement in $(\mathrm{mm})$

${ }^{*}$ Corresponding author: Ghulam A Hussaini, School of Natural and Built Environments, University of South Australia, GPO Box 2471 Adelaide South Australia 5001, Australia, Tel: +61 484200 111; E-mail: ghulam.hussaini@unisa.edu.au

Received April 23, 2017; Accepted August 23, 2017; Published August 29, 2017

Citation: Hussaini GA, Vogelsang N (2017) Numerical Simulation for SoilSuperstructure Interactive System. J Civil Environ Eng 7: 280. doi: 10.4172/2165$784 X .1000280$

Copyright: $\odot 2017$ Hussaini GA, et al. This is an open-access article distributed under the terms of the Creative Commons Attribution License, which permits unrestricted use, distribution, and reproduction in any medium, provided the original author and source are credited. 


\section{Statics and dynamics of soil-structure system}

The soil is modeled as non-homogenous elastic and plastic, which is governed by Hooke's law. Therefore, the elastic properties should be described by two parameters, the E-modulus and Poisson's ratio. Hooke's law is not appropriate for soils because soils are neither linear elastic nor isotropic. Poisson's ratio describes how a material deforms laterally when exposed to compressive or tensile stress. When a force is applied along one axis the material is strained parallel and orthogonally to that axis. The relation between these strains is represented by the ratio which is defined between $0<\mathrm{X}<0.5$. If the figure is set to 0.5 it means that the volume is unchanged during deformation [3]. For this research, random Poisson's ratio was tested as well as fixing the average value of 0.3 for the rest of the analysis. Plastic behavior is considered as soil irrecoverable deformation while elastic is taken the behavior when deformation is recoverable.

\section{Model Development}

\section{Creating a part/defining the model geometry}

The first step in creating the model is to define its geometry. The model is created with a three-dimensional, deformable body with a solid, extruded base feature. The following dimensions were used to create model.

Soil: $120 \mathrm{~m}^{3} \times 50 \mathrm{~m}^{3} \times 25 \mathrm{~m}^{3}$. The length of the soil sample was 120 $\mathrm{m}$, width $50 \mathrm{~m}$ and depth was $25 \mathrm{~m}$, the sample was than divided into 3 equal layers.

Concrete structure consists of two individual parts, walls and foundation, Foundation base $=35 \mathrm{~m} \times 20 \mathrm{~m} \times 5 \mathrm{~m}$ (with $5 \mathrm{~m}$ depth)

Rectangular Walls $=35 \mathrm{~m} \times 20 \mathrm{~m} \times 1 \mathrm{~m}$ (with $1 \mathrm{~m}$ wide and height $=10 \mathrm{~m}$ )

The analysis is executed for single structure case and at this stage, it is important to decide what system of units to use in the model because ABAQAS has no built-in system of units. Thus, the SI system of units is used. The next step in creating the model involves defining and assigning material and section properties to the part. Each region of a deformable body must refer to a section property, which includes the material definition.

In this model, non-linear elastic materials are created for both concrete structure and Hindmarsh clay (Table 2).

During the research, out of four variables only one variable was randomized, in every particular group of analyses. Under mentioned table is an example of such input data into ABAQUS (Table 3 ).

Each part created during these analyses, oriented in respected

\begin{tabular}{|c|c|c|c|c|}
\hline \multirow{2}{*}{ Shape of footing } & Flexible footing & Rigid footing & Mean s & S \\
\cline { 2 - 5 } & S at center & S at corner & Ism & Isor \\
\cline { 2 - 3 } & Iso & Isc & 0.85 & 0.79 \\
\hline Circular & 1 & & 0.95 & 0.88 \\
\hline Square & 1.12 & & -- & -- \\
\hline Rectangular & -- & 0.64 & 1.3 & 1.22 \\
\hline$L: b=2$ & 1.53 & \multirow{2}{*}{ circumference } & 1.83 & 1.72 \\
\hline 1.3 & 1.22 & & 2.25 & 2.12 \\
\hline$L: b=5$ & 2.1 & & 3.69 & $3 / 4$ \\
\hline
\end{tabular}

Table 1: Settlement influence factors for a homogeneous soil of semi-infinite depth.

\begin{tabular}{|c|c|c|}
\hline $\boldsymbol{P}\left(\boldsymbol{k G} / \mathbf{m}^{3}\right)$ & $\boldsymbol{v}$ & $\boldsymbol{E}(\boldsymbol{G P a})$ \\
\hline 2400 & 0.3 & 37 \\
\hline
\end{tabular}

Table 2: Properties of concrete structure.

\begin{tabular}{|c|c|c|c|c|c|c|c|}
\hline $\begin{array}{c}\text { La ye r } \\
\text { No }\end{array}$ & $\begin{array}{c}\text { Thickness } \\
(\mathbf{m})\end{array}$ & $\begin{array}{c}\text { Cumulative } \\
\text { thickness }(\mathbf{m})\end{array}$ & $\boldsymbol{P}\left(\mathbf{k G} / \mathbf{m}^{3}\right)$ & $\boldsymbol{v}$ & $\begin{array}{c}\boldsymbol{E} \\
(\mathbf{M P a})\end{array}$ & $\begin{array}{c}\text { Friction } \\
\text { Angle }\end{array}$ & Cohesion \\
\hline 1 & 8.33 & 8.33 & 1900 & 0.3 & 67 & 33 & 20000 \\
\hline 2 & 8.33 & 16.67 & 1900 & 0.3 & 72 & 33 & 20000 \\
\hline 3 & 8.33 & 25 & 1900 & 0.3 & 92 & 33 & 20000 \\
\hline
\end{tabular}

Table 3: Only elastic modulus randomly changed.

coordinate system and is independent of the other parts in the model. Although a model may contain many parts, it contains only one assembly. The geometry of the assembly is defined by creating instances of a part and then positioning the instances relative to each other in a global coordinate system [4]. Thus, the soil and concrete structure were assembled together.

Configuration is broadly categorized as an initial step and analysis steps.

- Initial step

ABAQUS/CAE creates a special initial step at the beginning of the model's step sequence and names it initial. It allows defining boundary conditions, predefined fields, and interactions that are applicable at the very beginning of the analysis.

\section{- Analysis steps}

The initial step is followed by one or more analysis steps. Each analysis step is associated with a specific procedure that defines the type of analysis to be performed during the step.

Finite element analyses can create very large amounts of output. ABAQUS allows controlling and managing this output so that only data required to interpret the results of the simulation are produced. Thus, the analysis is limited to give such a relevant output as displacement [5].

The interaction between contacting surfaces consists of two components, one normal to the surfaces and one tangential to the surfaces. The tangential component consists of the relative motion (sliding) of the surfaces and, frictional shear stresses.

The contact constraint is applied in ABAQUS when the clearance between two surfaces becomes zero. The surfaces separate when the contact pressure between them becomes zero or negative, and the constraint is removed. This behavior, referred to as 'hard' contact. The system is subjected to a small force which does not induce slip. Thus, for the tangential component, rough interaction is assumed as there is no slip between the surfaces [6]. Thus, for the normal behavior and the tangential behavior hard and rough contacts were used in all interactions.

\section{Applying boundary conditions and applied loads}

Prescribed conditions, such as loads and boundary conditions, are step dependent, which means that the step or steps in which they become active is specified accordingly.

- Applying boundary conditions

Boundary conditions are applied to those regions of the model where the displacements and/or rotations are known. Such regions may be constrained to remain fixed (have zero displacement and/or rotation) during the simulation or may have specified, nonzero displacements and/or rotations. Thus, a fixed boundary is set at the bottom and at the sides of the model.

- Applying a load 
The loads were assumed distributed load on walls and footings of concrete structure, in elastic analysis, $1 \mathrm{kPa}$ on walls and $2 \mathrm{kPa}$ on footings were applied, whoever in plastic analysis $40 \mathrm{kPa}$ on walls and $60 \mathrm{kPa}$ on footings were applied to examine the plastic characteristics on module.

\section{Designing the mesh}

The Mesh module contains tools that allow generating meshes on parts and assemblies created within ABAQUS/CAE. In the model, a structure meshing is used. Structure meshing is a technique that gives the most control over the mesh because it applies pre-established mesh patterns to model topologies [7]. Considerable care is taken to optimize the mesh size to get reliable results

\section{Creating, running, and monitoring a job}

Once defining a model is finished, the model is analyzed using the Job module. The job module allows interactively submitting a job for analysis and monitoring its progress.

Figure 1, shows the elastic deformation with random Poisson's ratio. The constant loading conditions used for elastic deformation during this research is $3 \mathrm{kPa}$, however only above example based on increase in load on the structure to $140 \mathrm{kPa}$, the maximum corner displacement recorded $25 \mathrm{~mm}$, while for centre the maximum displacement recorded $36.7 \mathrm{~mm}$, also as load increased the lateral displacement started over 4.4 $\mathrm{mm}$. That is why the elastic deformation was kept to $3 \mathrm{kPa}$ only to avoid lateral displacement; the example of it can be seen in Figure 2.

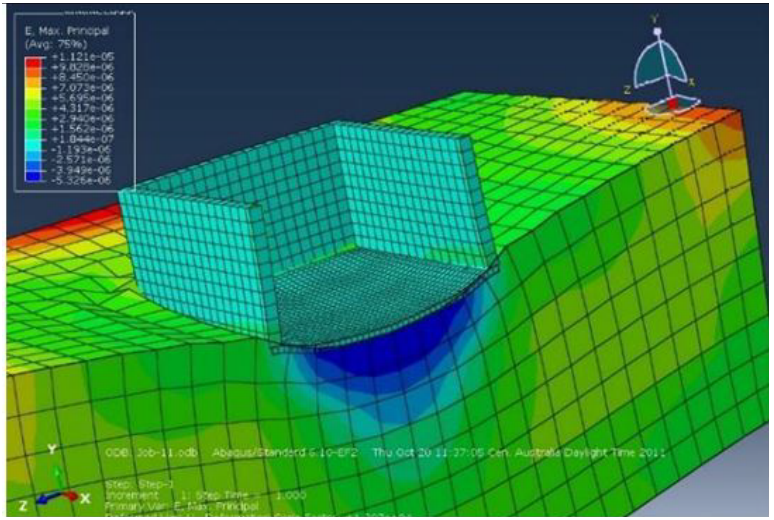

Figure 1: Elastic deformation with random Poisson's ratio.

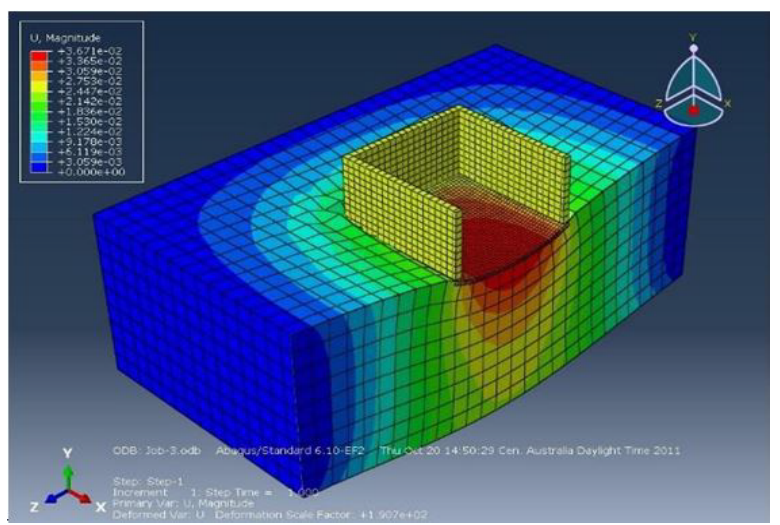

Figure 2: Max load of $140 \mathrm{kPa}$ and recorded max deflection at the centre.

\section{Method of Analysis}

\section{Elastic analysis}

The first point to consider is that the loads on the model need to be well within the elastic range of strain for all nodes of the model [8]. This ensures that there is no additional strain placed on nodes due to neighboring nodes plastically straining. The load, which is used for the elastic model, was sufficiently low to only be within the elastic range.

The second point that needs to be considered is a constant reference point to take measurements from, the displacement calculated by ABAQUS needs to be measured from the same point of each run of the model, the nodes chosen for this project were at the centre and corner, they are node 1452 and 2534 respectively. This eliminates minute discrepancies and differences between different nodes and gives a consistent displacement depending on just the varying parameter rather than the location.

The elastic analysis requires the variation of two parameters, these parameters are; Young's Modulus and Poisson's Ratio.

Analysis of Young's modulus: The method of analysing Young's Modulus is slightly different to the other parameters. The reason is that in the field Young's Modulus and density change with depth. This is an important feature and means that the model needs to vary with depth [9-11]. To do this five metre layers are incorporated into the model design to allow for this with the third and final layer being semi-infinite, Young's Modulus can be different for each layer.

An excel spread sheet is setup for Young's Modulus, since this analysis is only considering the variation of Young's Modulus, Poisson's Ratio is kept constant. The soil layers of the model are divided into three sections, each section has a different Young's Modulus with the top layer having the least and the bottom layer having the highest. This is achieved by dividing the entire possible range of Young's Modulus into three sections, the lower bound is the range for the first layer, the middle range is for the second layer, the upper bound is the range for the third layer, Young's modulus is then randomly chosen for each layer based on the layers available range. The spread sheet is then setup to have a progressive average of the displacement of the foundation's centre and the corner, when the graph of the progressive average plateau's, this represents that there is sufficient test results to characterize the parameter's displacement distribution [12-14].

Analysis of Poisson's ratio: The setup for Poisson's ratio is a bit easier than Young's modulus, for this analysis Poisson's ratio is assumed to be the same across all layers this may not reflect all field scenarios however variation of Poisson's ratio between layers is sufficiently small to be ignored [15].

To begin with an excel spread sheet is setup with both Young's Modulus and Poisson's Ratio, for this set of analysis Young's Modulus is kept constant and Poisson's Ratio varies [16]. The excel spread sheet is setup using the excel function "rand between" to choose a number between 20 and 40 , this number is then divided by 100 so that it is within the range of 0.2 and 0.4 , with each value being used for each run of ABAQUS.

\section{Plastic analysis}

The main point that needed to be considered in the plastic analysis was the requirement that the load on the structure needed to be increased to make sure as many points as possible were within the plastic range of strain. After a number of quick tests, a load of $50 \mathrm{kPa}$ was decided upon as this pushed the centre and corner measurement into plastic strain 
Citation: Hussaini GA, Vogelsang N (2017) Numerical Simulation for Soil-Superstructure Interactive System. J Civil Environ Eng 7: 280. doi: 10.4172/2165-784X.1000280

Page 4 of 8

without overstraining the soil in the model [17]. The same points were applied for the measurements as the elastic analysis. This gave us the best comparison possible between the varying of individual parameters and their effect on the displacement.

Analysis of internal angle of friction: The setup for the internal angle of friction was very similar to that of the previous elastic analysis, the main difference being that in the plastic analysis the Mohr-Coulomb plasticity was included in the analysis. The values for the elastic analysis were taken as the middle value of the parameter range; this represents the three ranges for the Young's Modulus and the range for Poisson's Ratio [7]. The additional parameters required for the Mohr-Coulomb plasticity were internal angle of friction and cohesion as the two, which we would eventually vary, and the dilation angle and the absolute plastic strain which were both left constant at 0.1 and 0 respectively.

An excel spread sheet, was created for the internal angle of friction, in this spread sheet the constant values that were used in the elastic analysis and cohesion were listed for each run. The excel function "rand between" was used to randomly choose a number for the internal angle of friction between the stated range of 25 to 43 . This was then used in each run of ABAQUS to find the displacement range and frequency [13].

Analysis of cohesion: The setup for the cohesion parameter is not different to the setup for the internal angle of friction beyond the difference in range and the Internal Angle of Friction becoming constant [18]. A spread sheet was setup, for cohesion with all the required parameters included and left constant, the cohesion was changed by using the excel function "rand between" to return a cohesion value between the stated 10 kilopascal and 30 kilopascal range, since the unit being used for this setup in ABAQUS is Pascals the excel function was set between 10,000 and 30,000. The value of cohesion was input into ABAQUS for each run of the model until the progressive average settlement of the chosen nodes of the model plateaued. This represented that enough data was acquired to setup the required frequency graphs.

\section{Displacement analysis}

The results that were obtained from the model for each parameter were then used to construct a histogram of the data, this would indicate the best probability distribution choice for each of the parameters $[11,16]$. The required values for the best probability distribution for each of the parameters were then found using the displacement obtained from ABAQUS, for each respective parameter. A graph of the predicted displacement probability distribution is then generated to indicate the probability function likely if millions of tests were performed. The theoretical settlement for each test, as calculated by equations, goes through the same process of finding the best probability function and predicted displacement probability distribution assuming, the theoretical distribution and the experimental distribution are consequently compared and discussed.

\section{Parameter Distribution}

Research was conducted into the typical ranges for each parameter of Hindmarsh clay which were required by ABAQUS.

The parameters that were required for the projects are, Young's Modulus, Poisson's Ratio, Internal Angle of Friction and Cohesion [19]. They are described in this section in relation to Hindmarsh clay, it is noted that Hindmarsh clay is considered a Silty Clay [4] this was particularly useful in finding the ranges of each parameter.

The ranges of each parameter are as follows in the Table 4 below:

^It should be noted that the average for Young's Modulus, Poisson's

\begin{tabular}{|c|c|c|c|c|}
\hline Variables & Min & Average & Max & Reference \\
\hline $\begin{array}{c}\text { Young's Modulus } \\
\text { (MPa) }\end{array}$ & 47.88 & $72.82^{*}$ & 97.76 & $\begin{array}{c}\text { Geotechnicallnfo.com } \\
\text { in 2007 }\end{array}$ \\
\hline $\begin{array}{c}\text { Poisson's Ratio } \\
\begin{array}{c}\text { Internal Angle } \\
\text { of F }\end{array}\end{array}$ & 0.2 & $0.3^{*}$ & 0.4 & $\begin{array}{c}\text { Environment UK, } \\
\text { viewed Oct in 2011 }\end{array}$ \\
\hline riction (Degrees) & 25 & $34^{*}$ & 43 & $\begin{array}{c}\text { Geotechnicallnfo.com } \\
\text { in 2007 }\end{array}$ \\
\hline Cohesion (kPa) & 10 & 20 & 30 & $\begin{array}{c}\text { Geotechnicallnfo.com } \\
\text { in 2007 }\end{array}$ \\
\hline
\end{tabular}

*It should be noted that the average for Young's Modulus, Poisson's Ratio and Internal Angle of Friction were not available. It was assumed that the average was in the middle of the range.

Table 4: Parameter ranges.

Center Progressive Average Settlement

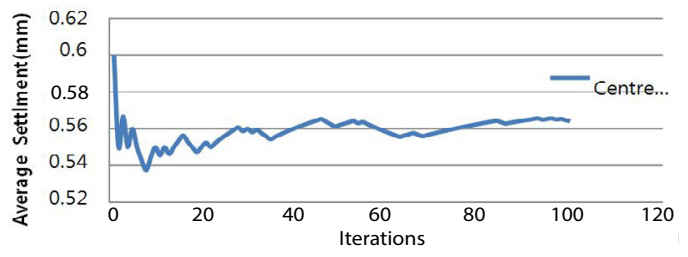

Figure 3: Young's Modulus varied, centre progressive average settlement.

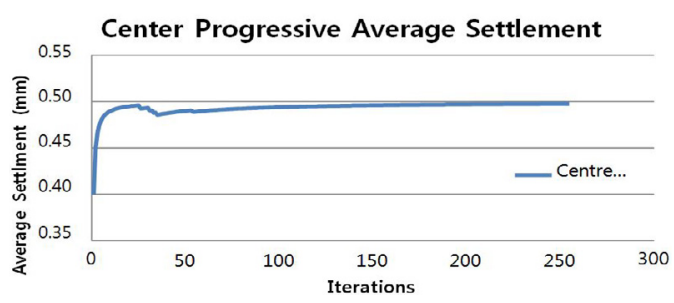

Figure 4: Poisson's Ratio varied, centre progressive average settlement.

Ratio and internal angle of friction were not available. It was assumed that the average was in the middle of the range.

Using the ranges stated in the previous sub-section an excel spread sheet was constructed; it contained columns for each parameter, with Young's Modulus having one column for each layer. This base worksheet was copied three more times, each representing a varying parameter [6]. Each of the varied parameters were randomized down the column using the "ran between" function, with the other parameters being held constant at their average (Young's Modulus had its range divided into three, one for each layer, so it was average of the layer's range).

\section{Results and Discussion}

The results from this investigation are stated in this section the full data is shown in appendices, all information in this section are important extracts from the data set, not the whole data set itself.

\section{Progressive average}

It needs to be noted that the elastic analysis was completed with a 3-kilopascal load, whereas the plastic analysis was completed with a 50-kilopascal load. The centre progressive averages, chosen as they took the longest to plateau, for each of the varied parameters are given below in the following graphs:

The centre progressive average settlement from Figure 3 seemed to begin to plateau around 100 iterations of the experiment. Once the progressive average seemed to plateau the average was assumed to not 
alter much more with more iterations. The change in Young's Modulus often produced rapid changes in soil displacement; this represents an early indication that Young's Modulus is a sensitive variable in soil settlement.

The centre progressive average shown in Figure 4 above does not show any rapid and sharp changes in average, it also plateaued quite early in the iterations at roughly 75 iterations. As there are no rapid and sharp changes in average it was an early sign that displacement is not very sensitive to changes in Poisson's Ratio.

As can be seen from Figure 5, the graph plateau is after 150 iterations, during which there were very few large sharp spikes in average. There are some smaller spikes in average though; this would indicate a change in Internal Angle of Friction has a medium amount of sensitivity to the displacement outcome.

As can be seen from Figure 6, the graph plateaued after 110 iterations however there were still spikes in average but centred on the same area, throughout the entire graph there are significant spikes in average. This gives an early indication of displacement's high sensitivity to changes in cohesion.

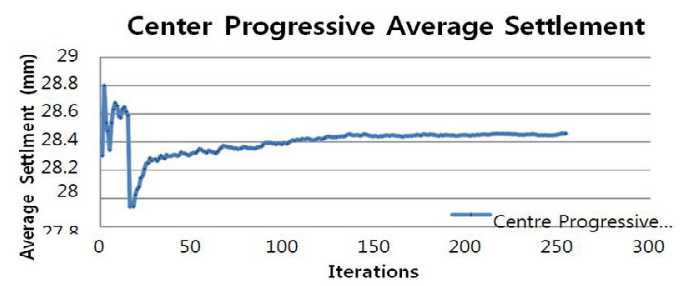

Figure 5: Internal angle of friction varied, centre progressive average settlement.

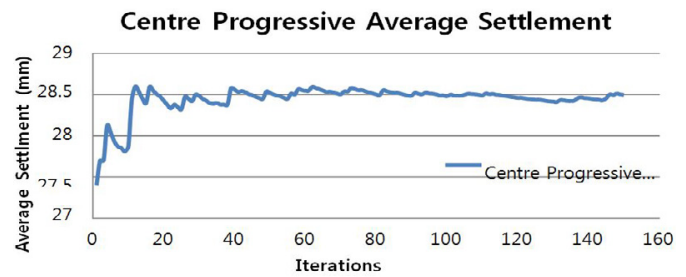

Figure 6: Cohesion varied, centre progressive average settlement.

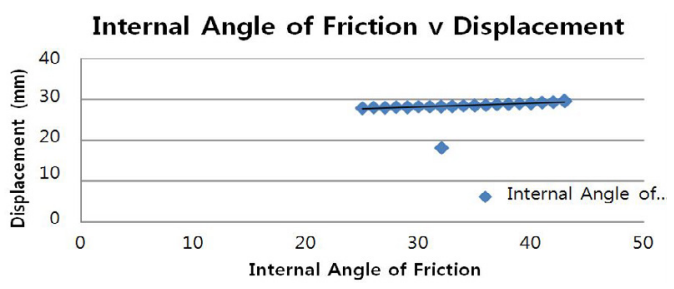

Figure 7: Internal angle of friction vs. displacement.

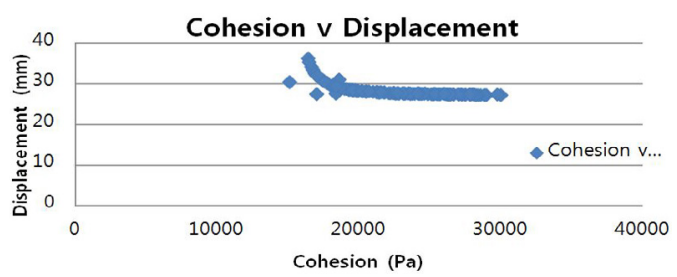

Figure 8: Cohesion vs. displacement.

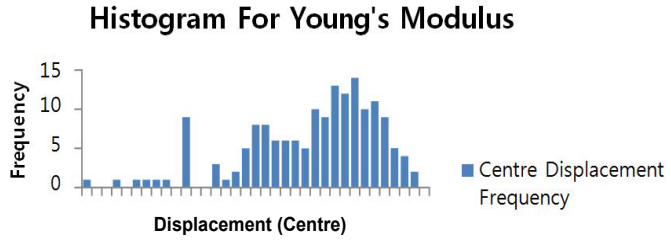

Figure 9: Young's Modulus centre histogram.

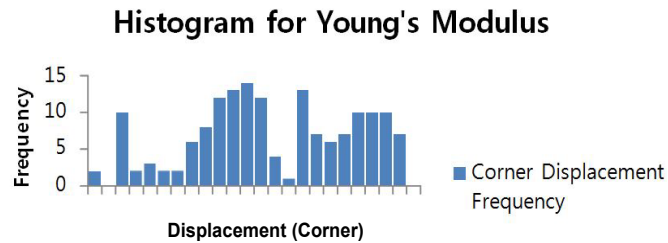

Figure 10: Young's Modulus corner histogram.

\section{Displacement}

The results from the experiment gave an early indication of sensitivity through the progressive average settlement graphs in the previous sub-section. The data has been displayed against the value of the varied parameter in question in this section to further investigate the displacement's sensitivity to change in each of the plasticity parameters. Only the plastic variables are being viewed as the data from the elastic analysis tended to bounce between two values, due to the low loading of the structure [20]. The graphs of this can be seen as follows of each of the plastic parameters.

Figure 7 above shows a graphical representation of the sensitivity of the displacement to changes in internal angle of friction. The low slope of the trend line shows that the Internal Angle of Friction is not a very sensitive variable. One major outlier is not on the trend line, this represents the presence of a small error to be discussed in the later titled section.

As shown in Figure 8 above, the cohesion seemed to have a high sensitivity to the outcome of the displacement but was dependent upon what the cohesion was, the lower the cohesion the higher the displacement. Overall, there are a couple of minor outliers that once again represent some sort of error present in the process and will be discussed further in the relevant section.

\section{Histograms}

The histograms are an important part of determining the type of probability density curve to be used to characterize the probability of a displacement outcome. This can also help to show whether enough data was obtained to properly characterize the probability of a soil settlement value. It should be noted that the histograms use the progressive average settlement values to construct the histograms [21]. The histograms shown in this section are ordered into the centre displacement and corner displacement for each of the parameters, they are as follows.

The histograms shown below are for the centre and corner respectively, it can be seen in Figure 9 that there appears to be a general shape of a normal distribution curve however in situations there are higher frequency outliers in the lower end of the displacement axis, this shows that the data obtained is reasonable but not the best. In Figure 10 , there does not appear to be any discernible shape to the histogram, there is a normal distribution curve beginning to shape however it still means that the data for Young's Modulus in general is reasonable but not the best $[21,22]$. 
The following two histograms are for the centre and corner displacement respectively by varying Poisson's Ratio. In Figure 11, there does appear to be excellent shape to histogram clearly showing a normal distribution curve, there is one outlier in the lower end of the displacement axis however, this is reasonable and of no major concern as it is consistent with a normal distribution curve. The data for the centre displacement appears to be of good quality and enough to properly characterize the displacement probability for Poisson's ratio.

In Figure 12 above, there is a very clear indication of a normal distribution curve, the peak is clearly centreed in the middle of the displacement range of the axis and is not skewed in either direction. This shows that enough data was collected to properly characterize the corner displacement. Overall, the data quality for this parameter is excellent and should properly characterize the displacement probability for Poisson's Ratio.

The following two histograms are of the centre and corner displacement respectively, the varying parameter is the Internal Angle of Friction. In Figure 13 below there is some indication of a normal distribution shape emerging from the histogram. The quality of data based from this is good as the shape is present in the histogram.

In Figure 14 above there is a very clear normal distribution curve

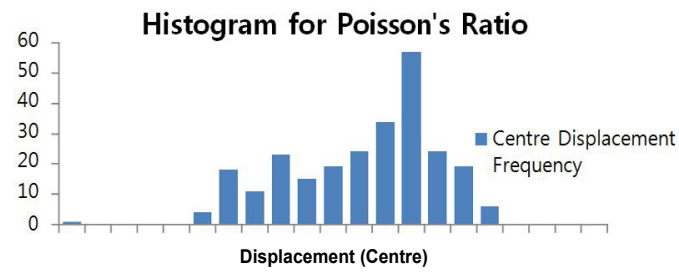

Figure 11: Poisson's Ratio centre histogram.

\section{Histogram for Poisson's Ratio}

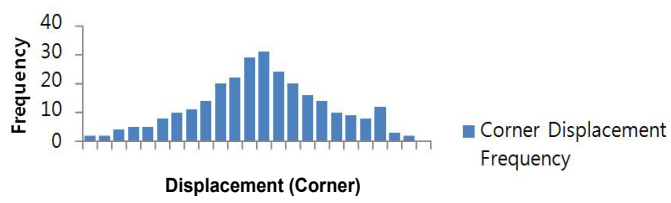

Figure 12: Poisson's Ratio corner histogram.

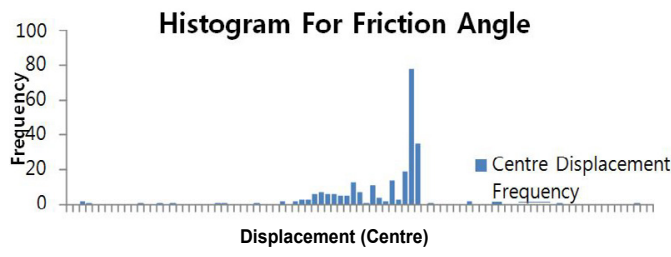

Figure 13: Internal angle of friction centre histogram

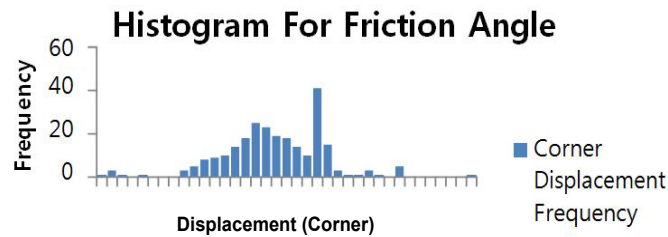

Figure 14: Internal angle of friction corner histogram. forming, this indicates a displacement probability curve shaped as such. There does appear to be some displacements that are more frequent than others so appear to alter the shape of the histogram, however overall the data for the Internal Angle of Friction is good enough to characterize the displacement probability curve.

The two following graphs are the centre and corner displacement histograms for the varied parameter cohesion. In Figure 15, there is a similar shape to the normal distribution curve that can be seen, the range of the histogram is quite broad. The quality of the data based off this histogram is good.

In Figure 16, there is a clear normal distribution curve appearing in the histogram. It is very clear and contains very few high frequency outliers. Overall, the data obtained for cohesion is of excellent quality and should be enough to properly characterize the displacement probability curve.

\section{Probability distributions}

The probability distributions are constructed by using the shape that is apparent in the histogram to construct an estimated displacement probability density curve [23]. This can be quite useful in finding the probability of a displacement being exceeded at a particular site. The probability distributions that were generated for each of the parameters are as follows.

In comparison to the histogram that was shown for both the centre and the corner in the previous sub-section, there does appear to be some significant differences. The spread of the data for the centre and corner sections in the histograms Figures 9 and 10 are more as it is based on the progressive average. The data therefore shows that the average settlement in Figure 17 for the centre slightly deviates from the progressive average centreed histogram.

The probability curves below, Figure 18 are of the displacement probability for both the centre and the corner. The biggest thing to note is that once again the corner probability distribution is less spread than the centre. This will be discussed in a later section.

As a comparison of Figure 18 to the Poisson's Ratio histograms of Figure 11 and Figure 12 for centre and corner respectively there appears to very close similarities between the centres of the progressive average histograms and the averages seen in the figure above. The spread of data is roughly the same as well as the corner does not deviate away from 0.4 too much and the centre does not deviate from 0.5 much more either.

It can be seen from Figure 19 that the spread of data for the corner displacement probability curve was very low especially when compared to the centre displacement probability curve which relatively speaking has a larger spread. This is in contrast the progressive average settlement histograms of Figures 13 and 14 which show that the average settlement spread was inverted, the centre had a very low spread and the corner had a larger spread. This seems to indicate that the average settlement will deviate very little from the centre but the outcome of that average settlement will be spread out and the inverse is the case for the corner.

As can be seen from Figure 20 below there is a similar spread of data for both the centre and the corner displacement probability curves. The corner is slightly more concentrated and will be discussed in a later section.

The above figure in comparison to the cohesion histograms for centre and corner Figures 15 and 16 are quite similar. The spread of data for the progressive average histogram and the above figure appear 
Citation: Hussaini GA, Vogelsang N (2017) Numerical Simulation for Soil-Superstructure Interactive System. J Civil Environ Eng 7: 280. doi: 10.4172/2165-784X.1000280

to have slightly different ranges however but the shape appears to be quite similar.

\section{Theoretical settlement}

The theoretical settlement was calculated using the equations mentioned in Section 3. After the calculation of the theoretical settlement, it became quite apparent that there was large difference in settlement, as it would often be twice as large as the values obtained through the ABAQUS experiment.

It could be attributable to the theoretical settlement calculation

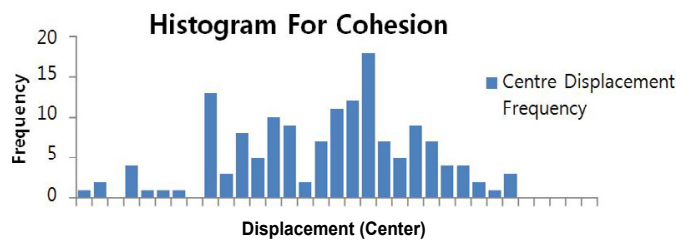

Figure 15: Cohesion centre histogram.

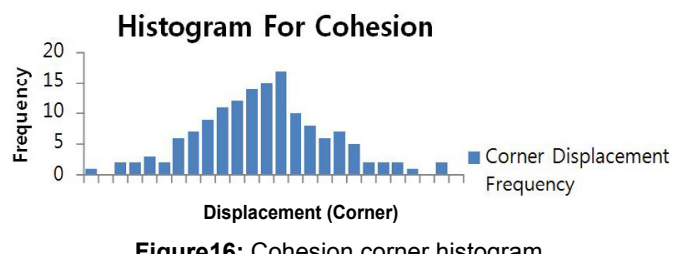

Figure16: Cohesion corner histogram.

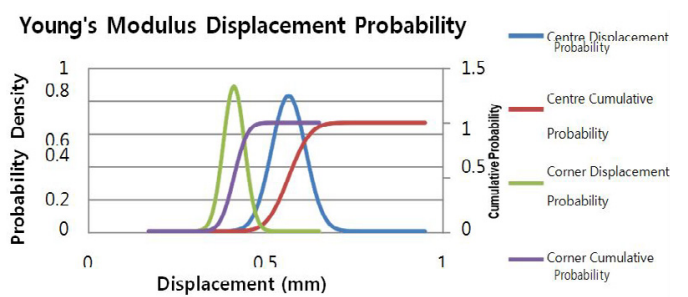

Figure 17: Young's Modulus displacement probability centre and corner.

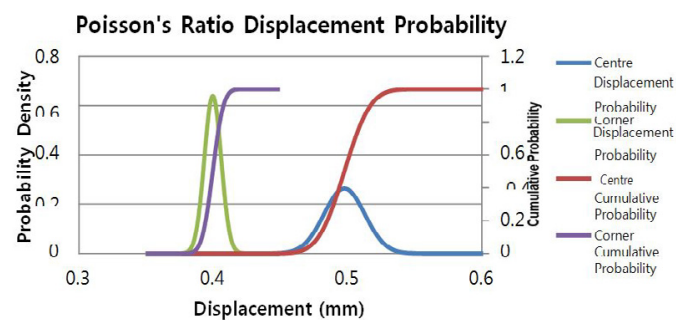

Figure 18: Poisson's Ratio displacement probability centre and corner.

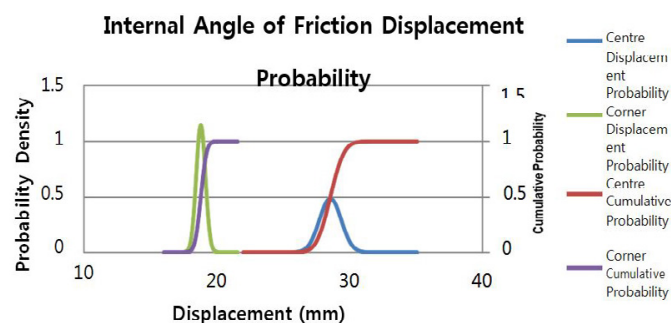

Figure 19: Internal angle of friction displacement probability centre and corner

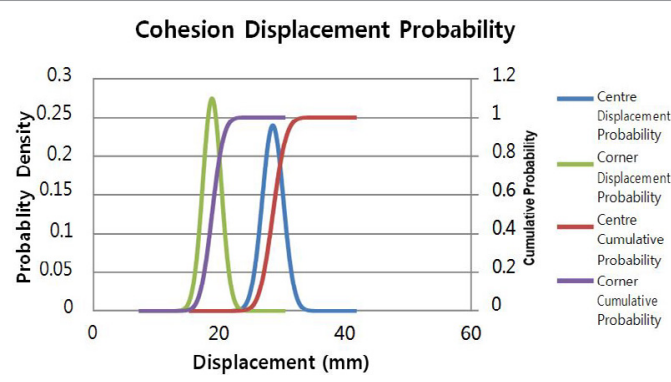

Figure 20: Cohesion displacement probability centre and corner

using the average Young's Modulus between the three layers not the settlement at each of the layers. It should also be noted that a large potential factor for this is that ABAQUS included the resistive force generated by the foundation [21,23] and walls itself whereas the theoretical settlement assumed all the load from the building was transferred to the soil.

The difference between the theoretical settlement and the practical values obtained from ABAQUS represent the role that is played by the foundation and the walls in resisting loading forces and reducing the transference to the soil.

\section{Recommendations and Conclusion}

The major outcome of this investigation has been the role that is played by the foundation and the structure itself in the resistance to loading and how this affects the soil beneath it. The investigation revealed the parameters, which effect the displacement most sensitively, are the two that seemed to affect the displacement the most were Young's Modulus and Cohesion.

The soil model which was created in ABAQUS indicated large strains under the 50-kilopascal load, due to the time restriction earthquake loading (lateral loading in general) could not be attempted. It is possible to make a prediction as to what the outcome would have likely been with further investigation, as it would be likely that since the 50 kilopascal was at the limit of the lower extremity of cohesion that the lateral loading would likely make the soil fail. As mentioned in Section 7.2 the settlement could not be calculated for cohesion less than 16.4 kilopascals as the strain was too large for ABAQUS and was assumed fail. This shows that if lateral loading was to be attempted a reduction in load would be required to properly evaluate the soil.

It can be seen in the graphs from Section 7.4 that the $90 \%$ confidence interval can be read from the cumulative probabilities curves for each of the parameters in the centre and the corner. It does need to be noted that due to the rounding error in ABAQUS the distribution is likely smaller than it would otherwise be therefore the settlement at this $90 \%$ confidence should be taken as an indication only.

The following are recommendations for future investigation:

- Create model in millimeters to increase precision.

- Complete more tests for each parameter to verify the probability curves; recommend at least 2000 per parameter.

- Work on varying multiple parameters to study the effect on the structure and soil.

- Make the model wider and higher to ensure it is semi-infinite.

- Model the effect of bigger or more buildings or both.

- Make load a varying parameter. 
Citation: Hussaini GA, Vogelsang N (2017) Numerical Simulation for Soil-Superstructure Interactive System. J Civil Environ Eng 7: 280. doi: $10.4172 / 2165-784 X .1000280$

In conclusion, the project provided an excellent opportunity to study the structure-soil interaction and the limitations of the system and was very useful and in learning and developing an interest in the topic.

\section{Acknowledgments}

It is an honor for us to thank our teachers, supervisors and examiners $\mathrm{Dr}$. Mizanur Rahman and Dr. Xing Ma for their invaluable contribution starting from inception to end of the project work. Especially, their extraordinary readiness and capability to help and give matured ideas was unforgettable.

We would also like to acknowledge the wonderful contribution of Dr. Donald Cameron. His support in many ways such as research provision, facility provision, giving constructive feedbacks on course work and welcoming spirit is worth mentioning. We owe our deepest gratitude to Barbara Hardy Centre to offset workshop costs for this project.

This project deals with simulation of the elastic and plastic response of a soilstructure system. It was carried out at the School of Natural and Built Environments, Division of Information Technology, Engineering and the Environment, University of South Australia, Australia.

\section{References}

1. Smith I (2006) Smith's elements of soil mechanics. (8th edn) Blackwell Publishing, USA.

2. Moghaddasi M, Cubrinovski K, Chase JG, Pampanin S, Carr A (2011) Probabilistic evaluation of soil- foundation-structure interaction effects on seismic structural response. Earthquake Engng Struct Dyn 40: 135-154.

3. Gabrielsson J (2007) Numerisk Simulering Av Stabilitet För Vägbank På Sulfidjord, Lileå Tekniska Universtet, Sweden.

4. Jaksa MB, Kaggwa WS (1992) Generalised geotechnical engineering design properties of the keswick and Hindmarsh Clays. University of Adelaide, Australia.

5. Clouteau D, Savin E, Aubry D (2001) Stochastic simulations in dynamic soilstructure interaction. Ecole Centrale de Paris. Meccanica 36: 379-399.

6. Davidovic N, Prolovic V, Stojic D (2010) Modeling of soil parameters spatia uncertainty by geostatistics, University of Nis, Faculty of Civil Engineering and Architecture. Serbia 8: 111-118.

7. http://environment.uwe.ac.uk/geocal/foundations/foundations.htm\#SETTLENU
8. http://www.geotechnicalinfo.com/youngs_modulus.html

9. http://www.geotechnicalinfo.com/angle_of_internal_friction.html

10. http://www.geotechdata.info/parameter/cohesion.html

11. Glen Elert (1999) Density of Concrete, Encyclopedia of scientific essays.

12. Goovaerts $P$ (2001) Geostatistical modelling of uncertainty in soil science. The University of Michigan, USA.

13. Gule E, Enunlu AK (2009) Investigation of dynamic behaviour of geo-synthetic reinforced soil retaining structures under earthquake loads. Springer. Bull Earthquake Eng 7: 737-777.

14. Ishihara K (2003) Soil behaviour in earthquake geo-technics. Oxford: Clarendon Press, UK.

15. Kholmyansky ML (2008) Dynamic soil-structure interaction considering random soil properties. International conference of international association for computer methods and advances in geo-mechanics.

16. Maheshwari BK, Watanabe $\mathrm{H}$ (2005) Dynamic analysis of pile foundations: effects of material nonlinearity of soil. Electron J Geotech Eng 10: 1-21.

17. Moghaddasi M, Cubrinovski M, Pampanin S, Carr AJ, Chase JG (2010) Soil-foundation-structure interaction effects on nonlinear seismic demand of structures. NZSEE Conference.

18. http://www.pedosphere.com/resources/bulkdensity/worktable_us.cfm

19. Popescu R, Deodatis G, Nobahar A (2005) Effects of random heterogeneity of soil properties on bearing capacity. Probabilistic Engineering Mechanics 20 324-341.

20. Raychowdhury P (2009) Effect of soil parameter uncertainty on seismic demand of low-rise steel buildings on denccse silty sand. Soil Dyn Earthq Eng 29: 1367-1378.

21. Ritter ME, Singh A (2001) Creative systems in structural and construction engineering. Balkema, Rotterdam, Netherlands.

22. Singh A (2001) Creative systems in structural and construction engineering CRC Press, USA.

23. Srbulov M (2008) Geotechnical earthquake engineering simplified analyses with case studies and examples. Springer, UK. 